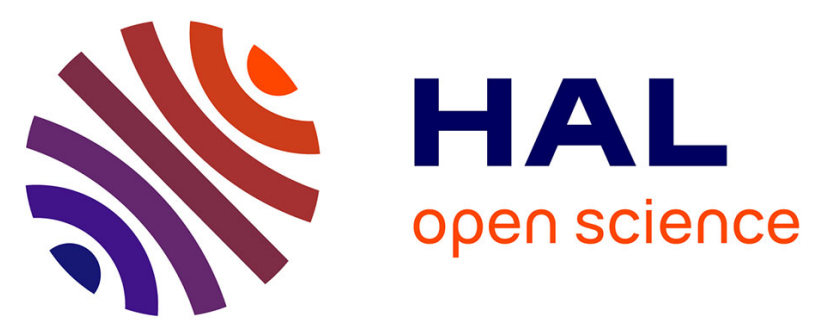

\title{
Investigation of laser-irradiated structure evolution and surface modification by in situ Micro-Raman spectroscopy
}

\author{
C. Li, Gang Wang, Xianghua Zhang, Y. Zhang
}

\section{- To cite this version:}

C. Li, Gang Wang, Xianghua Zhang, Y. Zhang. Investigation of laser-irradiated structure evolution and surface modification by in situ Micro-Raman spectroscopy. Vacuum, 2018, 155, pp.376-379. 10.1016/j.vacuum.2018.06.042 . hal-01835020

HAL Id: hal-01835020

https://hal-univ-rennes1.archives-ouvertes.fr/hal-01835020

Submitted on 13 Jul 2018

HAL is a multi-disciplinary open access archive for the deposit and dissemination of scientific research documents, whether they are published or not. The documents may come from teaching and research institutions in France or abroad, or from public or private research centers.
L'archive ouverte pluridisciplinaire HAL, est destinée au dépôt et à la diffusion de documents scientifiques de niveau recherche, publiés ou non, émanant des établissements d'enseignement et de recherche français ou étrangers, des laboratoires publics ou privés. 
Investigation of laser-irradiated structure evolution and surface modification by

in situ Micro-Raman spectroscopy

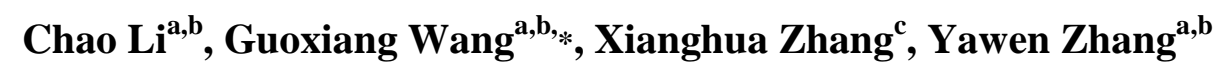

${ }^{a}$ Laboratory of Infrared Materials and Devices, The Research Institute of

Advanced Technologies, Ningbo University, Ningbo, Zhejiang 315211, China.

${ }^{b}$ Key Laboratory of Photoelectric Detection Materials and Devices of Zhejiang Province, Ningbo, Zhejiang 315211, China

${ }^{\mathrm{c}}$ Laboratoire des Verres et Ceramiques, Universite de Rennes I, 35042 Rennes

\section{Cedex, France}

The structure evolution and surface modification of the $\mathrm{ZnSb}, \mathrm{ZnSb}-\mathrm{Bi}$ and $\mathrm{ZnSb-NiO}$ phase-change films are detected by in situ Raman laser irradiation with the different laser power and irradiation time. The results show that undoped $\mathrm{ZnSb}$ films exhibit a phase transformation from amorphous to metastable phases at $250 \mathrm{~mW}$. The Bi-doped ZnSb films exhibit two different crystallization behaviors as the laser power increases. The films containing low Bi-doping concentration exhibit an amorphous-to-metastable phase transition, while the films containing high Bi-doping concentration directly crystallize into a mixture of new Bi-related crystalline phases and metastable $\mathrm{ZnSb}$ phases. As for $\mathrm{ZnO}$-doped $\mathrm{ZnSb}$ films, the structure evolution encounters an amorphous phase, metastable $\mathrm{ZnSb}$ phase or mixture of both. Identifying the structure evolution in the metastable phase by in-situ Raman measurement method is of great significance for phase change memory application.

Keywords: Thin films; Raman spectra; Laser irradiation; Metastable phases

* Corresponding author.

E-mail addresses: wangguoxiang@nbu.edu.cn (G. Wang) 
Phase-change memory (PCM) has the two-level data storage [1], which is due to the rapid and reversible switching of phase-change materials [2] between amorphous phase of high resistance state and crystalline phase of low resistance state upon heating [3]. The data storage capacity of two-level is low, which has become the major obstacle in the development of multi-level data storage. It is well known that the conventional germanium-antimony-tellurium (Ge-Sb-Te) phase-change films have three-state, such as amorphous, cubic and trigonal phases, which can lead to multi-level data storage properties [4]. However, the poor thermal stability and low crystalline resistance of GST is currently still a big challenge to apply in multi-level data storage.

In comparison, the novel phase change materials based on Te-free Zn-Sb ternary system have been extensively used as phase-change layer in non-volatile memory device due to its better thermal stability and higher crystalline resistance. Among the $\mathrm{Zn}-\mathrm{Sb}$ phase change materials, the crystal structure of $\mathrm{ZnSb}$ (the ratio of $\mathrm{Zn}$ to $\mathrm{Sb}$ is 1:1) alloy has been widely used and investigated [5,6]. It exhibits a metastable orthorhombic structure and a stable hexagonal $\mathrm{ZnSb}$ structure confirmed d by X-ray diffraction and transmission electron microscopy (TEM) in order to distinguish the distinct state [6]. However, the temperature span of intermediate resistance state for $\mathrm{ZnSb}$ films is rather narrow, which make the control of the resistance state being very difficult. Wang et al.[7] reported that the addition of $\mathrm{Bi}$ into the $\mathrm{GeTe}-\mathrm{Sb}_{2} \mathrm{Te}_{3}$ could result in the decreased crystallization temperature, which was correlated with the reduction in the crystalline activation energy. Thus, we introduce the $\mathrm{Bi}$ into $\mathrm{ZnSb}$ to decrease the phase transformation temperature so that we adopt in situ continuous Raman irradiation to observe the vibration modes in the metastable phases. 
The Raman spectra can record information based on atomic arrangement in amorphous marks in a crystalline layer of a phase-change material [8]. Due to the large difference in the optical reflectivity between the amorphous and crystalline state, structural information can be obtained based on the change in Raman mode, position and intensity [9]. When the laser irradiation power is relatively low, no obvious compositional change and no Raman vibration mode can be observed in an exposed region. Then, a bright spot may appear and become larger in size as the laser power increases beyond its crystallization temperature. However, the ablation may happen in the case of exposed samples with a higher laser power, because the laser irradiation induces temperature above its melting point [10].

Thus, we adjust laser power to irradiate the $\mathrm{ZnSb}$-based films in order to observe the structure evolution in terms of its Raman mode vibration. The paper is devoted to the in situ Raman studies of laser irradiation effect on amorphous materials intending to show and analyze phase changes in these materials with the evidence for sequential transitions from one phase to metastable phase with increasing laser power. Through systematic investigations on the relation between Raman mode variation and laser power, we confirm the existence of the intermediate phase.

The Bi-doped and NiO-doped $\mathrm{ZnSb}$ films with a thickness of $200 \mathrm{~nm}$ were deposited on Si substrate by using magnetron co-sputtering method with separate $\mathrm{Bi} / \mathrm{NiO}$ and $\mathrm{ZnSb}$ targets, respectively. The chamber was evacuated to $2 \times 10^{-5} \mathrm{~Pa}$, and then $\mathrm{Ar}$ gas was introduced at $0.3 \mathrm{~Pa}$. Undoped $\mathrm{ZnSb}$ films with the same thickness were also prepared for comparison. The composition of the ZnSb-based films was determined by energy dispersive spectroscopy (EDS). The structure evolution was monitored and measured by a laser confocal Raman spectra (Renishaw inVia, 
Gloucestershire, UK). The irradiation source for inducing phase change was an $\mathrm{Ar}^{+}$ laser with an wavelength of $785 \mathrm{~nm}$ and maximum laser power of $500 \mathrm{~mW}$ while selecting a grating $(\sim 1200 \mathrm{l} / \mathrm{mm})$ corresponding to the laser source. We altered scan conditions, the exposure time and laser power, by changing the acquisition tab of spectral acquisition setup. The exposure time is $15 \mathrm{~s}$ for laser irradiation. The 8 different laser powers $(\sim 0.25,0.5,2.5,5,25,50,250,500 \mathrm{~mW})$ were set available for laser irradiation. Since the initial laser power is very small, resulting in a poor signal-noise ratio (SNR) of the spectra, it is difficult to obtain real smooth Raman curve. The morphological characteristics of the films after Raman laser irradiation was observed by using a super-long depth-of-view optical microscope (VHX-1000E, Keyence) in a 2-D mode.

Fig.1 (a) shows the Raman spectra of $\mathrm{ZnSb}$ films irradiated by different laser power for $15 \mathrm{~s}$. It is found that a broad peak $\mathrm{G}$ at $\sim 155.7 \mathrm{~cm}^{-1}$ is reasonably assigned to the vibration of numerous wrong bonds formed in the as-deposited state. With the laser power increasing from 0.25 to $50 \mathrm{~mW}$, the amorphous nature can be kept. The higher laser power irradiation results in a reorganization of the amorphous network with the rupture of the wrong bonds and formation of energetically more stable heteropolar $\mathrm{Zn}-\mathrm{Sb}$ bonds. Subsequently, the two crystallization peaks A $\left(108.6 \mathrm{~cm}^{-1}\right)$ and $\mathrm{B}\left(144.6 \mathrm{~cm}^{-1}\right)$ appear at the laser power of $250 \mathrm{~mW}$. The two peaks shift towards a low wavenumber at $140.6 \mathrm{~cm}^{-1}$ and $104.3 \mathrm{~cm}^{-1}$ at $500 \mathrm{~mW}$, respectively. Comparing the peak positions with that in the Raman spectra for thermal-annealed $\mathrm{ZnSb}$ samples [11], we confirm that the Raman peaks attribution roughly coincides with the precipitation metastable $\mathrm{ZnSb}$ phases.

The structure evolution from amorphous to crystalline is observed clearly by the change in the surface morphology as shown in Fig.1(b). It records the laser-induced 
surface modification after in situ laser irradiation on the film surface. We observe the smooth surface morphologies of amorphous $\mathrm{ZnSb}$ films irradiated at 0.25, 0.5, 2.5, 5, 25 and $50 \mathrm{~mW}$. As the laser power increases to $250 \mathrm{~mW}$, the $\mathrm{ZnSb}$ film startes to crystallize, corresponding to the metastable phase. The surface morphology has an obvious long crystallization area (see dotted yellow circle). With further irradiating up to $500 \mathrm{~mW}$, it is noteworthy that the surface morphology of $\mathrm{ZnSb}$ film changes significantly and a dark center appeared, implying that the element ablation may happen so that the Si substrate can be exposed.

For Bi-doped ZnSb films, the Raman spectra with different laser powers from 0.25 to $500 \mathrm{~mW}$ for $15 \mathrm{~s}$ were shown in Figs.2(a)-(c). In the case of a lower Bi-doping concentration as shown in Fig.2(a), it is found that the amorphous broad peak $G$ is also kept until 50mW, while the position of the Raman peaks (A and B) in the crystalline state is the similar as that in undoped $\mathrm{ZnSb}$, indicating that the metastable phase is also precipitated in $(\mathrm{ZnSb})_{96.84}(\mathrm{Bi})_{3.16}$. Noteworthy, there are two new peaks $\mathrm{C}$ and D appeared. This may be related to the vibration of Bi-related crystalline phases. From the results in Fig.2(b) and (c), the Raman peaks of $\mathrm{ZnSb}$ films containing high Bi-doping concentration are very different from that in $\mathrm{ZnSb}$ films containing low Bi-doping concentration. Obviously, the $(\mathrm{ZnSb})_{82.75} \mathrm{Bi}_{17.25}$ and $(\mathrm{ZnSb})_{75.93} \mathrm{Bi}_{24.07}$ films exhibit crystallization behavior at the initial low laser power of $0.25 \mathrm{~mW}$. The result predicts that the films have been crystallized at room temperature with doping excess $\mathrm{Bi}$, which would deteriorate the thermal stability and cause crystallization. This is well agreement with the role of $\mathrm{Bi}$ investigated in previous reports on Bi-GST [7] and Bi-Sb-Te [12]. With the laser power increasing from 0.25 to $50 \mathrm{~mW}$ gradually, we can determine that the intensity of Raman peaks A and B is decreased compared with that in low Bi-doping concentration ZnSb. Different from 
Fig.2(b), the Raman peaks C and D of ZnSb films containing 24.07at\% Bi-doping concentration as shown in Fig.2(c) exhibits a sharper and stronger intensity while peaks A and B become weaker and broader. This illustrates that the initial metastable $\mathrm{ZnSb}$ phase is suppressed and new crystalline phases become dominated due to higher Bi-doping concentration. The $\mathrm{Bi}$, which lies in the same group as $\mathrm{Sb}$, has larger atomic radius $\left(\gamma_{\mathrm{Bi}}=0.163 \mathrm{~nm}, \gamma_{\mathrm{Sb}}=0.163 \mathrm{~nm}\right)$ [13], which is easier to enter the network structure of $\mathrm{ZnSb}$ film and replace $\mathrm{Sb}$ position. Thus, it may result in the generation of new Raman peaks originated from the vibrational modes of (Bi,Sb) and/or $\mathrm{ZnSbBi}$ crystalline phases.

Fig.3 (a) shows the Raman spectra of NiO-doped $\mathrm{ZnSb}$ films irradiated at different laser powers for $15 \mathrm{~s}$, respectively. The broad Raman peak $G$ of the $\mathrm{NiO}-\mathrm{ZnSb}$ films irradiated at $0.25 \mathrm{~mW}$ is observed, which implies the presence of an amorphous phase. With the laser power increasing, the amorphous nature of $(\mathrm{ZnSb})_{94}(\mathrm{NiO})_{6}$ films can be kept until $50 \mathrm{~mW}$. When the film is irradiated at $250 \mathrm{~mW}$, a mixture of amorphous and crystalline state has been appeared, just as the small peak A' and broad peak B'. Then, it is completely transferred into the metastable $\mathrm{ZnSb}$ phase at $500 \mathrm{~mW}$. The variation is very different from Fig.1 and Fig.2, illustrating that the addition of $\mathrm{NiO}$ into $\mathrm{ZnSb}$ improve the thermal stability, but the metastable phase can still be detected at higher $500 \mathrm{~mW}$ power. The corresponding surface modification has been depicted in Fig.3(b). The amorphous smooth surface is kept until 50mW. A small crystallization area is observed at $250 \mathrm{~mW}$, implying partial crystallization. With the laser power increasing, the crystallization area becomes large obviously.

In summary, the Raman mode vibration of the $\mathrm{ZnSb}$-based films exposure to the different laser powers from $0.25 \mathrm{~mW}$ to $500 \mathrm{~mW}$ has been studied by using Renishaw Raman Spectrometer. The results show that the amorphous and crystallization states 
are successfully found with the distinguishable Raman vibration modes at different laser powers. For $\mathrm{ZnSb}$ films, the amorphous state can be kept until $50 \mathrm{~mW}$, and then the films were crystallized into crystalline state. The precipitated crystal types were confirmed to be metastable $\mathrm{ZnSb}$ phases. For Bi-doped $\mathrm{ZnSb}$ films, the Raman evolution of $(\mathrm{ZnSb})_{96.84} \mathrm{Bi}_{3.16}$ films exhibit the similar crystallization process as the undoped $\mathrm{ZnSb}$ films. As the Bi-doping concentration increases, both $(\mathrm{ZnSb})_{82.75} \mathrm{Bi}_{17.25}$ and $(\mathrm{ZnSb})_{75.93} \mathrm{Bi}_{24.07}$ exhibit an initial crystallization with four Raman peaks. Meanwhile, the peaks A and B are gradually decreased and new peaks C and D are increased due to higher Bi-doping concentration, which can lead to no phase transformation from amorphous to crystalline states. For NiO-doped $\mathrm{ZnSb}$ films, the complete metastable phase appears at a higher power of $500 \mathrm{~mW}$ due to the better thermal stability. The experimental results suggest that the in-situ Raman measurement method is valuable for studying the transformation characteristics of phase change materials and has better sensitivity to characterize phase transition behavior.

\section{Acknowledgments}

This work was financially supported by the National Natural Science Foundation

of China (Grant No. 61604083), the Natural Science Foundation of Ningbo City, China (Grant No. 2017A610094) and was sponsored by the K. C. Wong Magna Fund in Ningbo University.

\section{References}

[1] M. Wuttig, N. Yamada, Phase-change materials for rewriteable data storage, Nat. Mater. 6 (2007) 824-832.

[2] D. Loke, T.H. Lee, W.J. Wang, L.P. Shi, R. Zhao, Y.C. Yeo, T.C. Chong, S.R. Elliott, Breaking the speed limits of phase-change memory, Science 336 (2012) 
1566-1569.

[3] G.W. Burr, M.J. Breitwisch, M. Franceschini, Phase change memory technology, J. Vac. Sci. Technol. B 28 (2010) 223-262.

[4] T.H. Lee, D. Loke, S.R. Elliott, Microscopic mechanism of doping-induced kinetically constrained crystallization in phase-change materials, Adv. Mater. 27 (2015) 5477-5483.

[5] T.J. Park, D.H. Kim, S.J. Park, S.Y. Choi, S.M. Yoon, K.J. Choi, N.Y. Lee, B.G. Yu, Phase transition characteristics and nonvolatile memory device performance of $\mathrm{Zn}_{\mathrm{x}} \mathrm{Sb}_{100-\mathrm{x}}$ alloys, Jpn J. Appl.Phys. 46 (2007) L543-L545.

[6] Y.M. Chen, G.X. Wang, X. Shen, T.F. Xu, R.P. Wang, L.C. Wu, Y.G. Lu, J.J. Li, S.X. Dai, Q.H. Nie, Crystallization behaviors of $\mathrm{Zn}_{\mathrm{x}} \mathrm{Sb}_{100-\mathrm{x}}$ thin films for ultralong data retention phase change memory applications, CrystEngComm, 16 (2014) 757-762.

[7] K. Wang, D. Wamwangi, S. Ziegler, C. Steimer, M. Wuttig, Influence of Bi doping upon the phase change characteristics of $\mathrm{Ge}_{2} \mathrm{Sb}_{2} \mathrm{Te}_{5}$, J. Appl. Phys. 96 (2004) 5557.

[8] F.I. Allen, E.Kim, N.C. Andresen, C.P. Grigoropoulos, A.M. Minor, In situ TEM Raman spectroscopy and laser-based materials modification, Ultramicroscopy 178 (2017) 33-37.

[8] T. Matsunaga, N. Yamada, Crystallographic studies on high-speed phase-change materials used for rewritable optical recording disks, Jpn. J. Appl. Phys. 43 (2004) 4704.

[9] J. Fu, X. Shen, Y.S. Xu, G.X. Wang, Q.H. Nie, C.G. Lin, T.F. Xu, R.P. Wang, Structural evolution of $\mathrm{Ge}_{2} \mathrm{Sb}_{2} \mathrm{Te}_{5}$ films under the $488 \mathrm{~nm}$ laser irradiation, Mater. Lett. 88 (2012) 148-151.

[10] W. Gawelda, J. Siegel, C.N. Afonso, V. Plausinaitiene, A. Abrutis, C. Wiemer, 
Dynamics of laser-induced phase switching in GeTe films, J. Appl. Phys. 109 (2011) 123102.

[11] C. Li, G.X. Wang, D.F. Qi, D.T. Shi, X.H. Zhang, H. Wang, Suppression for an intermediate phase in ZnSb films by NiO-doping, Sci. Rep. 7 (2017) 8644.

[12] R.E. Simpson, D.W. Hewak, P. Fons, J.Tominaga, S.Guerin, B.E. Hayden, Reduction in crystallization time of Sb:Te films through addition of $\mathrm{Bi}$, Appl. Phys. Lett. 92 (2008) 141921.

[13] G.X. Wang, X. Shen, Q.H. Nie, F. Chen, X.S. Wang, J. Fu, Y. Chen, T.F. Xu, S.X. Dai, W. Zhang, R.P. Wang, Te-based chalcogenide films with high thermal stability for phase change memory, J. Appl. Phys. 111 (2012) 093514. 


\section{Figure captions}

Fig. 1 (a) Raman spectra and (b) surface morphologies of $\mathrm{ZnSb}$ films irradiated at different laser powers from 0.25 to $500 \mathrm{~mW}$.

Fig. 2 Raman spectra of (a) $(\mathrm{ZnSb})_{96.84} \mathrm{Bi}_{3.16}$, (b) $(\mathrm{ZnSb})_{82.75} \mathrm{Bi}_{17.25}$ and (c) $(\mathrm{ZnSb})_{75.93} \mathrm{Bi}_{24.07}$ films irradiated at different laser powers from 0.25 to $500 \mathrm{~mW}$.

Fig. 3 (a) Raman spectra and (b) surface morphologies of $\mathrm{ZnSb}-\mathrm{NiO}$ films irradiated at different laser powers from 0.25 to $500 \mathrm{~mW}$. 


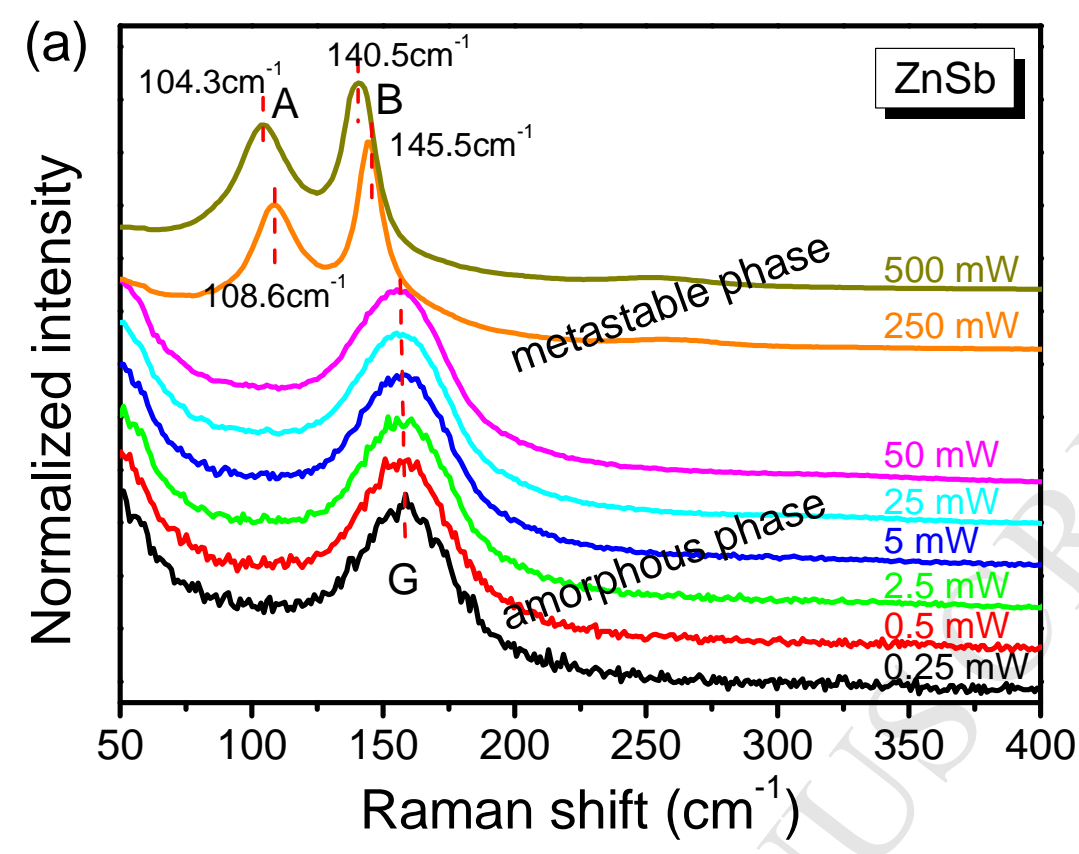

(b)

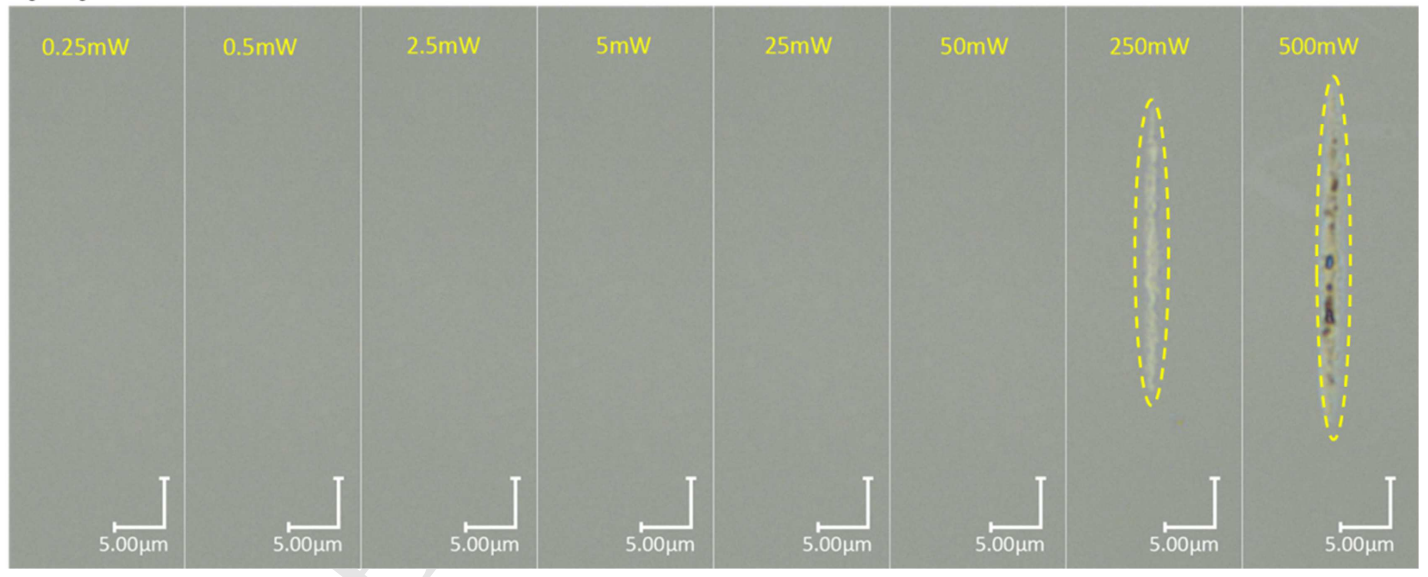

Fig.1 

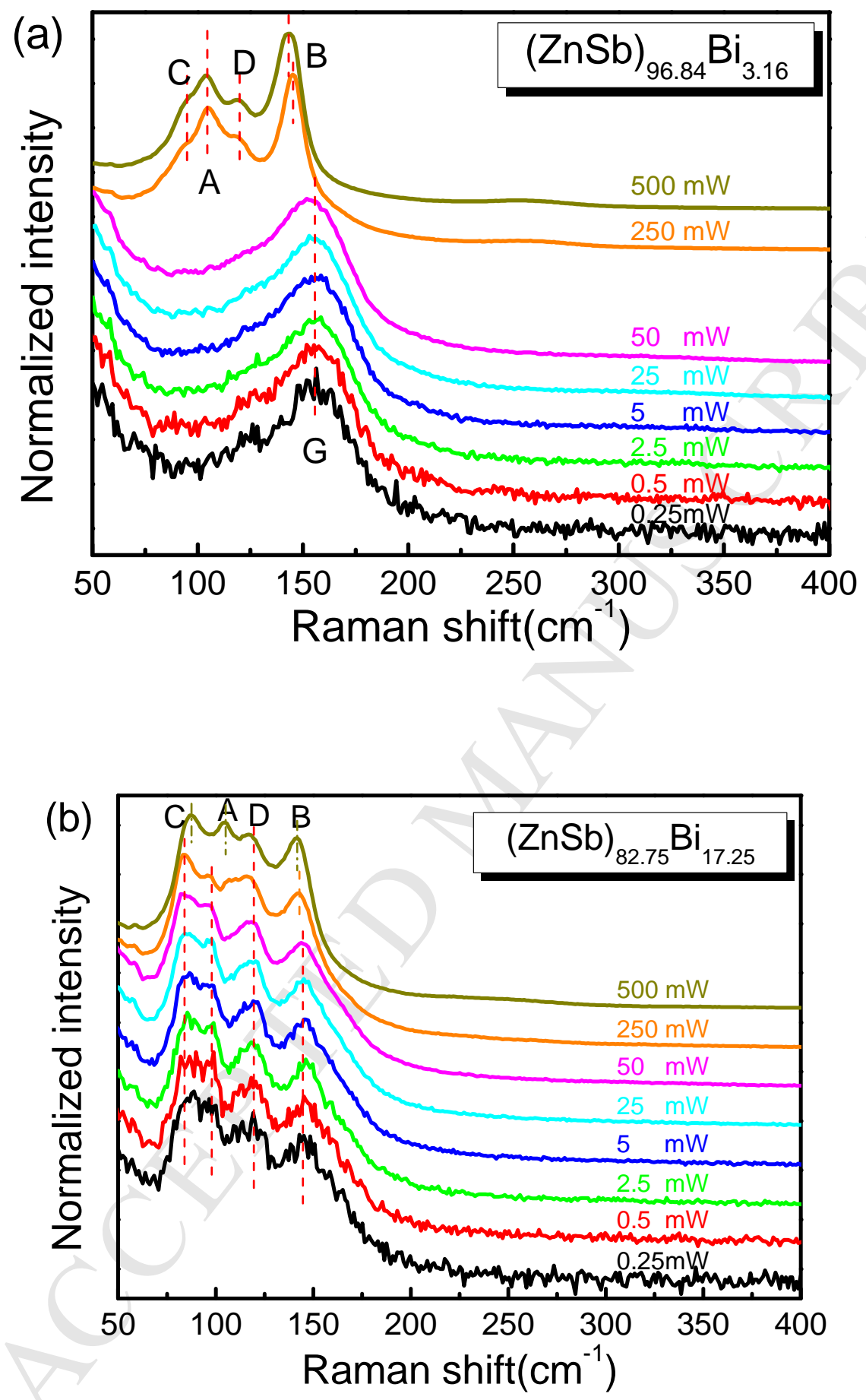


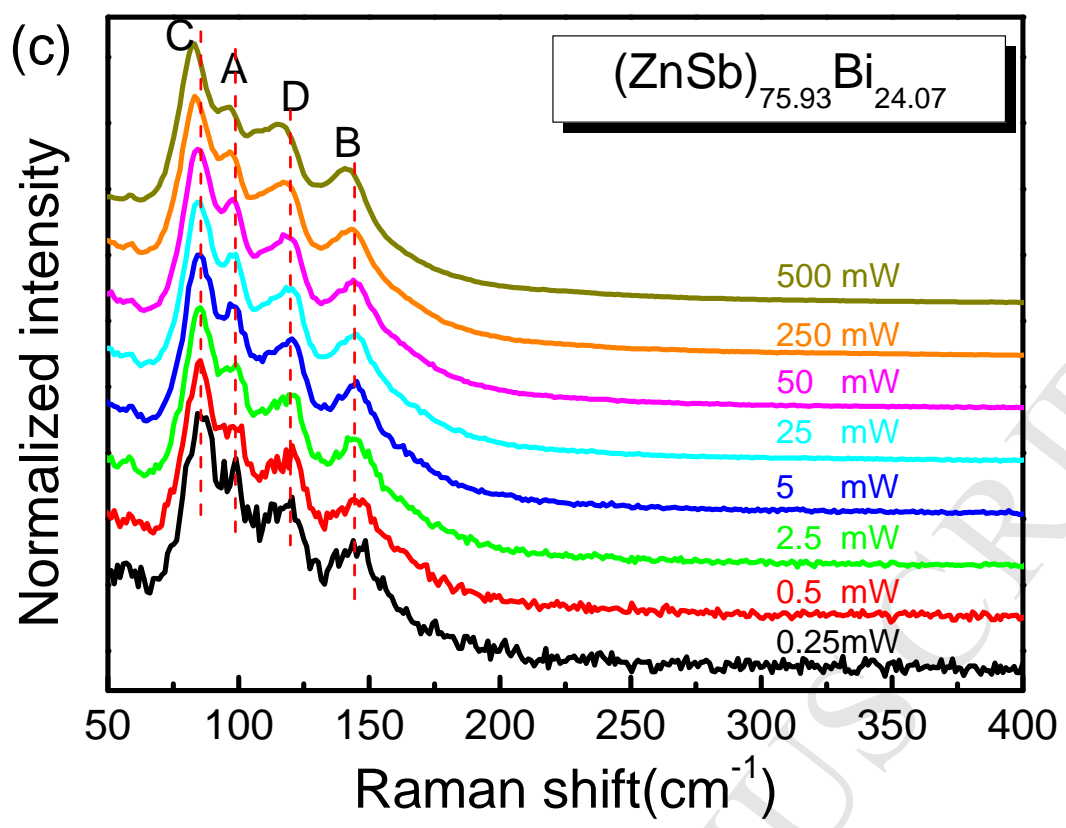

Fig.2 


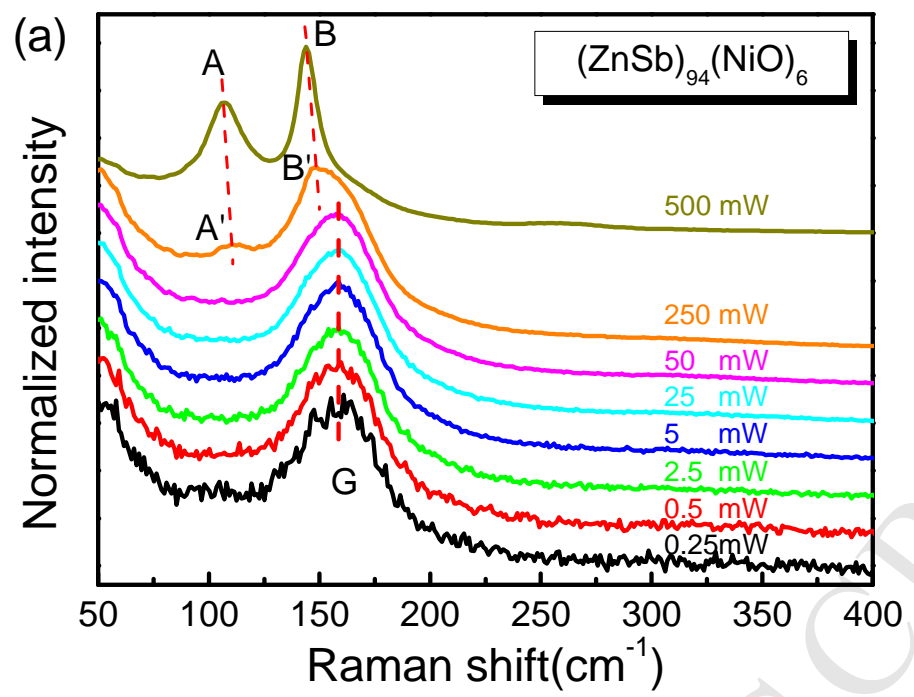

(b)

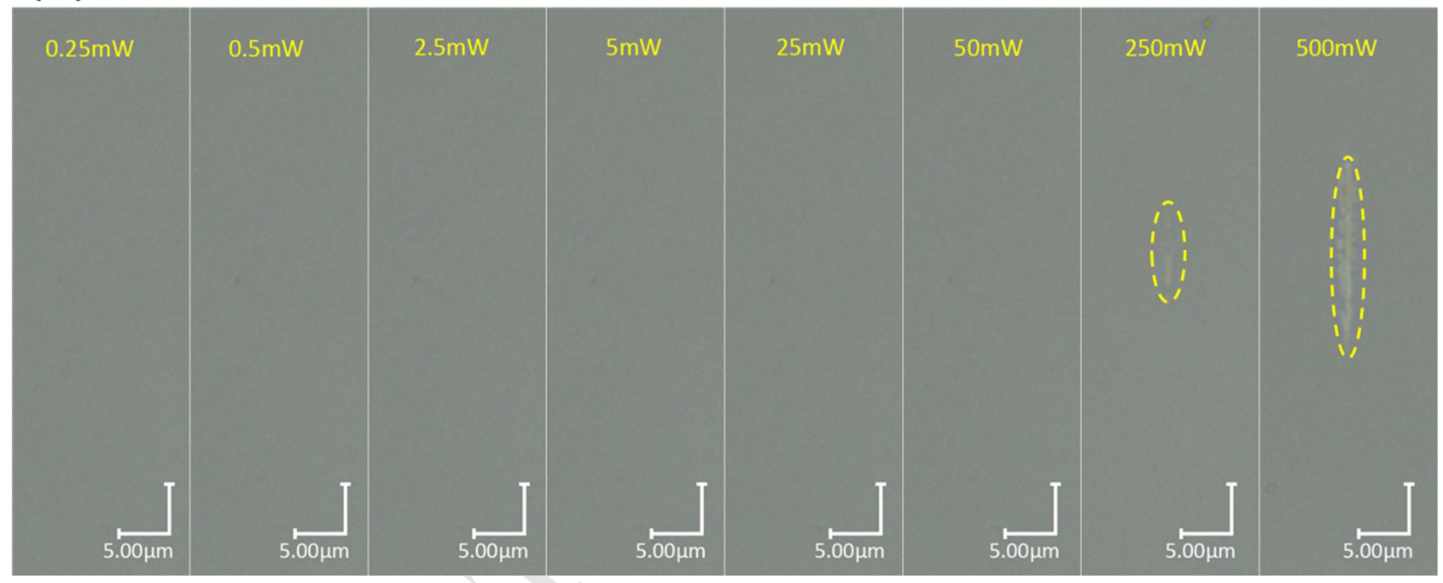

Fig.3 
- We demonstrate a continuous real-time $785 \mathrm{~nm}$ laser strategy to manipulate metastable states.

- Raman vibrational mode in metastable phases is clearly observed to confirm phase transition.

- A different phase-change behavior on the various $\mathrm{ZnSb}$-based films is distinguished. 